\title{
Self-Protection and Averting Behavior, Values of Statistical Lives, and Benefit Cost Analysis of Environmental Policy
}

\author{
GLENN C. BLOMQUIST* \\ gcblom@uky.edu \\ Department of Economics and Martin School of Public Policy and Administration, Gatton College of \\ Business and Economics Building 335H, University of Kentucky, Lexington, KY 40506-0034, USA
}

Received July 28, 2003; Accepted December 8, 2003

\begin{abstract}
Situations in which risk is at least partly a matter of choice provide opportunities to analyze behavior and estimate the willingness to pay for small changes in mortality risks. Individuals engage in household production of health and safety as long as the value of the gain in risk reduction is worth the money, time, and any disutility necessary to produce the reduction in risk. This paper reviews values of statistical life inferred from choices about highway speeds, traveler use of protective equipment, crashworthiness of motor vehicles, and housing location near Superfund sites. The best estimates, close to $\$ 4$ million in year 2000 dollars, are valuable complements to estimates from labor and constructed markets. Interestingly some evidence suggests that values for children and seniors are not less than middle-aged adults. Issues of risk perception and other challenges related to estimation are discussed.
\end{abstract}

Keywords: value of statistical life, mortality risks, benefit cost analysis, self-protection

JEL Classification: D13, D61, I12, J17

\section{Introduction}

Individuals can be observed in a variety of activities that affect their health and safety. Protective behavior is evident in motorist choice of automobile type, safety equipment such as seat belts, and speed of travel. Choices concerning safety helmets,

*An earlier version was presented at "Economic Valuation of Mortality Risk Reduction: Assessing the State of the Art for Policy Applications," an Environmental Policy and Economics Workshop held by the U.S. Environmental Protection Agency in Silver Spring, MD, on November 6-7, 2001 under EPA Cooperative Agreement R-82957201-0. Comments from Shoshana-Grossbard-Shechtman, Paul Hansen, Bryan Hubbell, Magnus Johannesson, Ted Miller, Laura Taylor, John Whitehead, workshop participants at EPA, Lund University, Stockholm School of Economics, and University of Kentucky, and several anonymous reviewers are appreciated. Helpful comments were also received from participants in a Southern Committee on Resource and Environmental Economics session at the Southern Economic Association meetings held in New Orleans, LA on November 24-26, 2002. Nicole Owens deserves special thanks for her encouragement and support in her role as project officer. I alone am responsible for the views in this paper. I thank too, the Centre for Health Economics, Department of Economics, Stockholm School of Economics where I was visiting on sabbatical when the first draft of this paper was written. 
cigarette smoking and installation of fire alarms change risks of death that individuals experience. Choice of residence when housing markets encompass Superfund sites influences the amount of risk that individuals face. Visits to health clinics for preventive care can reduce risks to health. The purpose of this paper is to review studies which estimate values of mortality risks based on the tradeoffs which individual consumers make. The common feature is that the estimates of values of small changes in mortality risks are implied by observable consumer behavior as individuals protect themselves against, or avert, risk. These values of mortality risks, for convenience, are sometimes referred to as "values of life" or "values of statistical life" (VSL). Interest in estimates of these values exists, in part, because the U.S. Environmental Protection Agency (EPA), the Department of Transportation, and other agencies evaluate policies and regulations that are expected to have impacts on individuals' health and safety and their mortality risks. Benefit cost analysis (BCA) of such policy requires VSL estimates.

This review is made with a constructively critical eye. It is potentially too costly to go with a destructively critical review because it could be counterproductive by fostering the mistaken notion that the whole methodology and entire body of evidence on VSL are unreliable. Such a review can make it easier for critics of BCA to disregard accomplishments, mistakenly abandon valuation, and promote an absolutist position that the concept of valuing mortality risks is immoral. ${ }^{1}$ A case can be made that economists take for granted that there is substantial agreement that individual willingness to pay for changes in risk is the best way to think about valuing the policy benefits and that sound, theoretically based methods exist for estimating VSL. ${ }^{2}$ A great deal has been learned about valuing mortality risks since estimation of willingness to pay for risk changes began nearly 30 years ago.

\section{Frameworks for estimating values of mortality risks based on averting behavior}

The thought of inferring individuals' values of reductions in mortality risks from their behavior intended to influence risk is appealing. Situations in which risk is at least partly a matter of choice provide opportunities to analyze behavior and estimate the willingness to pay (WTP) for risk reductions or willingness to accept (WTA) compensation for risk increments. These situations can involve choices among various types of work in the labor market, or the situations can involve choices in consumption activity. Self-protection or averting behavior in consumption, i.e., household production, is the focus of this paper. The theory for understanding these activities is built on the foundation laid by Jacob Mincer $(1962,1963)$ in his household framework, Gary S. Becker (1965) in his theory of allocation of time, and Isaac Ehrlich and Gary S. Becker (1972) in their theory of self-insurance and self-protection. The New Home Economics has been a useful framework for analyzing behavior with respect to physical risk. There are two closely related models that guide thinking about valuing changes in mortality risks. ${ }^{3}$ 


\subsection{The basic model}

A basic model with the present period and one future period captures the essence of estimating risk tradeoffs in consumption. ${ }^{4}$ Let the individual maximize expected utility, $E(U)$, that consists of utility in the first period, $U\left(C_{1}, S\right)$, and expected utility in the second period, $P U\left(C_{2}\right)$, where $U$ is a well-behaved single period utility function, $C_{i}$ is composite consumption in period $i, i=1,2, P$ is the probability of survival to period 2, and $S$ is protective health or safety activity in which the individual can engage. The production function for changing $P$ is left general as $P=P(S)$. $P^{\prime}$, the marginal product of averting behavior, is the reduction in the mortality risk. $P^{\prime}$ is assumed to be positive and diminishing. Averting activity can affect utility directly with $U_{S}$ negative if $S$ generates disutility or $U_{S}$ positive if averting activity generates utility. Expected utility is described by the following equation:

$$
E(U)=U\left(C_{1}, S\right)+P U\left(C_{2}\right)
$$

Differentiating equation (1), holding $E(U)$ constant, and solving for $d C_{1} / d \mathrm{P}$ yields

$$
d C_{1} / d P=-U\left(C_{2}\right) / \lambda P
$$

where $\lambda$ is the marginal utility of consumption (or income). Equation (2) shows the marginal rate of substitution between consumption and the probability of survival, or the marginal willingness to tradeoff current consumption for reductions in mortality risk (increases in the probability of survival). Although changes in $P$ are exogenous at this point, i.e., no averting behavior yet, several implications follow: (1) Willingness to pay for reductions in mortality risk is not a single value but depends on several factors that vary among individuals and circumstances. Willingness to pay will differ depending on $U(\cdot), C_{2}, P$, and $\lambda$. (2) The tradeoff depends on the base level of risk and will be smaller as the probability of survival $(P)$ increases. (3) The tradeoff depends on future consumption $\left(C_{2}\right)$, but it increases with increases in the utility of future consumption (or income or earnings) and not directly with future earnings. Changes in the marginal utility of income $(\lambda)$ may act to partly offset this effect.

Maximization of $E(U)$ is subject to the budget constraint, that the present value of expenditures on consumption and averting behavior, cannot exceed the present value of income,

$$
C_{1}+q S+d C_{2}=w T+d w T+A
$$

where $q$ is the cost of averting behavior, $d$ is the factor that discounts the amount in period 2 back to the present, $w$ is the wage rate, $T$ is time available for work in each period, and $A$ is the present value of nonlabor income. The cost of averting behavior, $q$, is composed of a money cost " $m$ " and a time cost, $a w t$, where " $a$ " is a factor which relates the value of time in averting activity to the wage rate, and " $t$ " is the time input into averting activity. 
The first order condition of interest is

$$
P^{\prime} U\left(C_{2}\right) / \lambda=q-\left(U_{S} / \lambda\right)
$$

The left-hand side of equation (4) is the marginal benefit of averting activity and the right-hand side is the marginal cost. Individuals engage in household production of health and safety as long as the value of the gain in risk reduction is worth the money, time, and any disutility necessary to produce the reduction in risk. Because risk is partly endogenous, it is possible to infer a VSL from averting behavior.

The value of a gain in the probability of survival (or reduction in mortality risk), is shown by the term, $U\left(C_{2}\right) / \lambda$, which is the monetary value of the utility of future consumption. Let this value be $V$ so that

$$
V \equiv U\left(C_{2}\right) / \lambda
$$

Notice that if equation (4) is solved for $V$, the value can be expressed as

$$
V=\left[q-\left(U_{S} / \lambda\right)\right] / P^{\prime}
$$

If for convenience of comparability $V$ is evaluated for a unit $(0-1)$ change in $P$, then $V$ is an estimate of VSL, value of statistical life. So, the value of a change in mortality risk for a unit change in $P$ is

$$
V S L=\left[m+a w t-\left(U_{S} / \lambda\right)\right] / P^{\prime}
$$

If, for example, it is known that the sum of the components of cost shown in brackets is $\$ 400$ per period and the change in the mortality risk per period is 0.0002 , then the VSL implied is $\$ 2$ million.

Each component of the equation presents a challenge in estimating VSL. The marginal monetary cost, $m$, is sometimes negligible for averting activity. It is sometimes estimated by an annual average cost. Marginal inputs of time, $t$, are sometimes small and sometimes substantial. The value of time spent in producing changes in mortality risks can equal the market wage rate, $w$, for the individual, or be some proportion of it, $a w$, as in most motor vehicle travel. The monetary worth of the marginal utility of the averting activity, $U_{S} / \lambda$, may be trivial, or may be a major cost, such as has been the case with manual (nonpassive) seat belts in cars. Estimating $P^{\prime}$ may be simple if expert estimates are available and individuals engaging in averting behavior perceive the changes in risks to be the same as the experts. Any misperception of risk makes estimating the perceived $P^{\prime}$ more challenging. Several of these components that are typically necessary for estimating VSL based on averting behavior will be discussed below.

\subsection{The life cycle model}

While a model with one future period is useful for understanding the basic tradeoff between mortality risk and consumption, a multi-period model with uncertain lifetime allows derivation of individual WTP for changes in mortality risks that would 
occur at different stages of the life cycle. Life-cycle models can define, for example, individual WTP now for a change in the conditional probability of survival in 10 years. These models can be useful for considering environmental policy that is expected to reduce future mortality risks. From life-cycle models have followed several implications that have shaped expectations about VSL estimates. Some testable implications are: ${ }^{5}$ (1) generally WTP declines with age, (2) under plausible conditions WTP exceeds discounted present value of future earnings, (3) WTP declines with latency, the length of time in the future when risk will be reduced, and (4) WTP now for a risk reduction in year $t$ is equal to WTP in year $t$ for that risk reduction discounted back to the present.

Current research continues to probe. For example, Per-Olov Johansson (2002) uses a life-cycle model to demonstrate that, in contrast to the first implication listed above, there is no obvious age pattern for WTP for mortality risk reductions over the life cycle. Brian W. Bresnahan and Mark Dickie (1995) discuss the implications of endogenous risk and other issues in using values based on averting behavior in policy evaluation. In this paper estimates of VSL based on self-protection and averting behavior are reviewed, and issues in using the basic model are discussed. Some of the empirical results reviewed are surprising given the implications of life-cycle models, at least as we currently understand them.

\section{Estimates of values of mortality risks based on self-protection and averting behavior in consumption}

\subsection{Previous reviews}

Interest in estimates of values of mortality risk reductions has produced several relatively recent reviews. ${ }^{6}$ W. Kip Viscusi's (1993) survey of the literature covers all types of studies and includes a summary of studies based on tradeoffs in consumption, or what he calls "outside of the labor market." There are seven early studies on highway speeds, seat belt use/nonuse, smoke detectors, housing prices and air pollution, and auto purchases. The average of the VSL estimates shown in Viscusi's Table 5 summary of these studies is $\$ 1.6$ million in year 2000 dollars. $^{7}$

Ted R. Miller (1990) also reviewed VSL estimates from all types of studies and using 47 (unadjusted) VSL estimates that he considered sound, he found an average VSL of $\$ 3.9$ million in 2000 dollars for the U.S. Later, using the previously reviewed studies and 21 additional estimates, Ted. R. Miller (2000) does a meta-analysis of international studies. The average of the 12 countries for which he has estimates plus the U.S. is also $\$ 3.9$ million in 2000 dollars. ${ }^{8}$ Differences in income, base risk levels, opportunities for reducing risk, availability of health care, culture, and other factors can influence values of mortality risks. The fact that Miller finds the average VSL to be similar is interesting, but should not be interpreted as strong evidence for VSL being equal in all countries. On the contrary, Miller reports an estimate for Taiwan, for example, that is less than $30 \%$ of that for the U.S. 
Rune Elvik (1995) performs a meta-analysis of 169 estimates of values of mortality risk changes. Table 1 is based on his summary of 11 averting behavior studies, see Elvik (1995, Appendix C, p. 19). The average of the VSL estimates he reports is $\$ 3.0$ million 2000 dollars if all values except for children and motorcyclists are included. One feature of Elvik's review is that he notes whether or not each study has a test of rationality, or risk perception, and whether the analysis uses individual or aggregate data. Elvik considers these two characteristics to be indicators of high relative validity.

The most recent review, by Arianne de Blaeij et al. (2002), is a meta-analysis of all types of studies that estimate VSL based on a tradeoff related to traffic safety.

Table 1. Elvik's summary of studies of averting behavior by road users.

\begin{tabular}{|c|c|c|c|c|c|c|c|}
\hline Author and publication year & $\begin{array}{l}\text { Type } \\
\text { of unit }\end{array}$ & $\begin{array}{l}\text { Sample } \\
\text { size }\end{array}$ & $\begin{array}{l}\text { Road } \\
\text { user }^{\text {b }}\end{array}$ & $\begin{array}{l}\text { Test of } \\
\text { rationality }\end{array}$ & $\begin{array}{l}\text { Base } \\
\text { risk }^{\mathrm{d}}\end{array}$ & $\begin{array}{l}\text { Risk } \\
\text { change }^{d}\end{array}$ & $\begin{array}{l}\mathrm{VSL}^{\mathrm{e}} \\
\text { (millions, } \\
\text { US \$) }\end{array}$ \\
\hline Melinek (1974) & Aggr & 1 & Ped & No & 0.035 & 0.035 & 1.1 \\
\hline $\begin{array}{l}\text { Debapriya Ghosh, Dennis Lees, } \\
\text { and William Seal (1975) }\end{array}$ & Aggr & 1 & Car & No & - & - & 1.1 \\
\hline Jones-Lee (1977) & Aggr & 1 & Car & No & - & - & 5.2 \\
\hline Blomquist (1979) & Indiv & 5517 & Car & Yes & 30.3 & 15.1 & $1.0^{\mathrm{f}}$ \\
\hline Jondrow, Bowes, and Levy (1983) & Aggr & 1 & Car & No & - & - & 2.9 \\
\hline Winston and Mannering (1984) & Indiv & 220 & Car & No & 12 & 12 & 2.2 \\
\hline Atkinson and Halvorsen (1990) & Aggr & 112 & Car & No & 19 & 19 & 5.2 \\
\hline Blomquist and Miller (1992) & Indiv & 5378 & Car & Yes & 7.4 & 3.3 & 2.8 \\
\hline \multirow{2}{*}{$\begin{array}{l}\text { (published as Blomquist, Miller, } \\
\text { and Levy (1996)) }\end{array}$} & Indiv & 934 & Car-child ${ }^{\mathrm{g}}$ & Yes & 3.6 & 2.6 & 6.5 \\
\hline & Indiv & 178 & $\begin{array}{l}\text { Motor } \\
\text { cyclist }^{h}\end{array}$ & Yes & 77 & 22 & 1.7 \\
\hline Dreyfus and Viscusi (1995) & Indiv & 1775 & Car & No & 19.6 & - & 5.5 \\
\hline
\end{tabular}

Source: Based on Elvik (1995), Appendix, Part D.

${ }^{\text {a }}$ The data unit is either aggregated or individual. An example of an aggregated data unit is average speed on highways.

${ }^{\mathrm{b}}$ The type of roadway user can be pedestrian, car driver, or motorcycle rider. The Blomquist and Miller estimate of $\$ 6.5$ million is inferred from drivers' use of child safety seats and belts for passengers who are less than 5 years of age.

${ }^{\mathrm{c}}$ Tests examine understanding of probability concepts or conformity to normative axioms of rational choice.

${ }^{\mathrm{d}}$ Deaths per 100,000 motor vehicles.

${ }^{\mathrm{e}}$ All money values are reported in year 2000 US dollars. Values are multiplied by 1.227 to convert from the 1992 dollars reported by Elvik to 2000 dollars using the Consumer Price Index for all urban consumers.

${ }^{\mathrm{f}}$ This value is reported in 2000 dollars. It converts the estimate in 1978 dollars reported in Blomquist (1979) to 2000 dollars. The value of 1.2 reported by Elvik appears to be based on the assumption that the Blomquist estimate was reported in 1972 dollars.

${ }^{\mathrm{g}}$ This value is inferred for children under 5 years based on driver use/nonuse of child safety seats and belts.

${ }^{\mathrm{h}}$ This value is inferred for motorcyclists based on their use/nonuse of helmets. 
Included are four studies and 10 estimates that are inferred from public agency programmatic decisions rather than individual behavior. While this type of study reveals something about public decision making, the values are different in nature from the values estimated from individual self-protection, averting behavior. The public tradeoffs do not directly inform about individual WTP. de Blaeij et al. report that the average of the VSL estimates in their Table 1 is $\$ 4.7$ million. A weighted average of estimates with and without the public tradeoffs implies that the preferred average VSL excluding the public tradeoffs is $\$ 4.2$ million in year 2000 dollars.

These reviews find that VSL estimates based on averting behavior in consumption tend to be less than estimates from averting behavior in the labor market based on risk compensating wage differentials or estimates from stated preferences in hypothetical or constructed markets. This relationship will be discussed further after considering the most recent studies of averting behavior in consumption.

\subsection{A review of recent studies of averting behavior in consumption}

Table 2 provides a summary of eight relatively recent studies that estimate VSL based on averting behavior in consumption. The first four analyze choices about highway speeds and roadway user use of protective equipment and infer VSL from tradeoffs between risk reductions and combinations of money, time, and disutility. The second four analyze choices in motor vehicle and housing markets using hedonic analysis of prices and infer VSL from tradeoffs between product prices and either vehicles with different designs that affect safety or houses with various cancer risks due to nearby Superfund sites. Through hedonic analysis the marginal implicit prices for mortality risk are estimated. The range of values for adults is something less than $\$ 1.7$ million to $\$ 7.2$ million in year 2000 dollars. The average value for adults is approximately $\$ 4.5$ million if $\$ 1.5$ million is used for the speed/fatality study and averages are used for the two studies with a range reported. Four very recent studies are worth more detail.

Speeds on interstate highways: One recent study was presented by Orley Ashenfelter and Michael Greenstone (2002) at a session in honor of Sherwin Rosen at the 2003 AERE/ASSA meetings. They estimate the VSL from changes in speeds on interstate highways. In 1987 federal law was changed to allow states to raise the speed limit on rural interstates from 55 to $65 \mathrm{mph}$. Their estimates are based on laws being changed so that motorists can make tradeoffs for time savings at the expense of bearing greater mortality risks. Motorists are assumed to base their behavior on the actual tradeoff of risks realized. This assumption is the same as is typically used in the labor market in which workers are assumed to make the tradeoff between higher wages and the mortality risks that actually occur. ${ }^{9}$

Ashenfelter and Greenstone analyze speeds and road fatalities for 28 states for which they can get data for the period 1982-1993. Based on models which include state-by-road-type and year-by-road-type fixed effects, they estimate that speeds 
Table 2. U.S. studies of self-protection and averting behavior in consumption that estimate VSL, 19902002.

\begin{tabular}{|c|c|c|}
\hline Author (year) & Behavior and tradeoff (year) & $\begin{array}{l}\text { Best Estimate of VSL (range), } \\
2000 \text { US dollars, millions }\end{array}$ \\
\hline $\begin{array}{l}\text { Ashenfelter and } \\
\text { Greenstone (2002) }\end{array}$ & $\begin{array}{l}\text { Speeds and fatalities on interstate highways } \\
\text { with higher speed limits, 1982-1993 }\end{array}$ & $\begin{array}{l}\$ 1.7 \text { as upper bound } \\
\text { Typical vehicle occupant }\end{array}$ \\
\hline $\begin{array}{l}\text { Jenkins, Owens, } \\
\text { and Wiggins (2001) }\end{array}$ & $\begin{array}{l}\text { Bicycle helmet use with fatality risk } \\
\text { reductions and costs, } 1997\end{array}$ & $\begin{array}{l}\$ 4.3 \text { adult } \\
\$ 2.9 \text { child } 5-9 \\
\$ 2.8 \text { child } 10-14 \\
\text { Users of helmets }\end{array}$ \\
\hline $\begin{array}{l}\text { Blomquist, Miller, } \\
\text { and Levy (1996) }\end{array}$ & $\begin{array}{l}\text { Car seat belt use with fatality risk reductions } \\
\text { and time and disutility costs, } 1983\end{array}$ & $\begin{array}{l}\$ 2.8-4.6 \text { adult }^{\mathrm{a}} \\
\$ 3.7-6.0 \text { child under }^{\mathrm{a}} \\
\$ 1.7-2.8 \text { motorcyclist } \\
\text { a } \\
\text { Typical driver or rider }\end{array}$ \\
\hline $\begin{array}{l}\text { Carlin and } \\
\text { Sandy (1991) }\end{array}$ & $\begin{array}{l}\text { Child safety seat use with fatality risk } \\
\text { reductions with time and money costs, } 1985\end{array}$ & $\begin{array}{l}\$ 0.8 \\
\text { Child under } 5\end{array}$ \\
\hline $\begin{array}{r}\text { Mount et al. (2001, } \\
\text { workshop paper) }\end{array}$ & $\begin{array}{l}\text { Hedonic analysis of motor vehicle prices } \\
\text { with fatality risks, } 1995\end{array}$ & $\begin{array}{l}\$ 7.2 \text { adult }^{\mathrm{a}} \\
\$ 7.3 \text { child }^{\mathrm{a}} \\
\$ 5.2 \text { elderly }^{\mathrm{a}} \\
\text { Typical vehicle occupant }\end{array}$ \\
\hline $\begin{array}{l}\text { Dreyfus and } \\
\text { Viscusi (1995) }\end{array}$ & $\begin{array}{l}\text { Hedonic analysis of car prices with fatality } \\
\text { risk, } 1988\end{array}$ & $\begin{array}{l}\$ 3.8-5.4 \\
\text { Typical car occupant }\end{array}$ \\
\hline $\begin{array}{l}\text { Atkinson and } \\
\text { Halvorsen (1990) }\end{array}$ & $\begin{array}{l}\text { Hedonic analysis of car prices with fatality } \\
\text { risk, } 1978\end{array}$ & $\begin{array}{l}\$ 5.3 \\
(4.6-5.4) \\
\text { Typical car occupant }\end{array}$ \\
\hline $\begin{array}{l}\text { Gayer, Hamilton, } \\
\text { and Viscusi (2000) }\end{array}$ & $\begin{array}{l}\text { Hedonic analysis of housing prices with } \\
\text { fatality risk near Superfund sites, } 1988-1993^{\mathrm{b}}\end{array}$ & $\begin{array}{l}\$ 4.7 \\
(4.3-5.0) \\
\text { Typical resident }\end{array}$ \\
\hline
\end{tabular}

No adjustment is made for differences in base level risk.

Source: Author.

${ }^{a}$ Higher value reflects adjusted for risk perception bias by multiplying by 1.634 .

${ }^{\mathrm{b}}$ Values after release of the Remedial Investigation of the Superfund sites. Values are for a statistical cancer case.

increased by approximately $3.5 \%(2 \mathrm{mph})$ and fatalities increased by approximately $35 \%$ in states which adopted the higher speed limit. They calculate the time savings associated with the increase in speeds, approximately 125,000 hours saved per life lost. This tradeoff between time gained and life lost implies an upper bound on VSL of approximately $\$ 1.7$ million in year 2000 dollars if time is valued at the wage rate.

Ashenfelter and Greenstone argue that their empirical analysis should be interpreted as reflecting the preferences of the median driver/voter. The estimate is an upper bound because the tradeoff is observed only for states and drivers in which the 
value of the time savings exceeds the cost of the fatalities. Motorists would not trade off the mortality risks if the risks were worth more than the savings in time. State legislators would not permit the tradeoff if they thought the mortality risks were worth more than the savings in time. In the second part of their paper they attempt to recover the structural estimates of the VSL based on analysis of the tradeoff in each of the states. The estimates of this "average" tend to be slightly lower than the upper bound estimate, but they are imprecisely estimated.

Ashenfelter and Greenstone's upper bound estimate of $\$ 1.7$ million appears to be reasonably robust statistically, but their estimate depends on values used for valuing motorists' time, number of passengers per vehicle, and perceptions of risks and time savings as well. These parameters matter. To adjust for the average number of occupants per vehicle from the assumed value of 1 to the average number of 1.7 would increase their VSL estimate by $70 \%$. To adjust for the value of time from the assumed ratio of 1 for (value of time)/wage to 0.6 as used in Glenn Blomquist, Ted R. Miller, and David T. Levy (1996) would decrease their VSL estimate to only $60 \%$ of what it is. While these two adjustments just about offset one another, if an adjustment is made for misperception of risk by motorists and the value of 1.634 is used as in Blomquist, Miller, and Levy (1996), then their upper bound estimate of VSL would be $\$ 2.8$ million in 2000 dollars. ${ }^{10}$

Bicycle helmets, seat belts, child safety seats, and motorcycle helmets: Robin R. Jenkins, Nicole Owens, and Lanelle Benbench Wiggins (2001) calculate the VSL implied by use of bicycle helmets and find it to be approximately $\$ 4.3$ million in 2000 dollars for adults who purchase and wear the helmets. They consider their estimate to be a lower bound because buyers (and presumably users) find it worth at least as much as the cost to gain the added protection. Including time and disutility costs would increase the implied value and reinforce the claim that the estimate is a lower bound if only money costs are relevant to the use decision. However, their estimated VSL is an upper bound for bicyclists who are not buyers (and users) under the same assumption of time and disutility costs being equal to zero. If potential time and disutility costs are important for all bicyclists and those costs are different for users and nonusers, then their estimate is not necessarily an upper bound for nonusers. Because the calculations are based on aggregate data, it is not clear what the VSL is for the average bicyclist. This aspect aside, their study is noteworthy in that it is one of only a few that estimate VSL for children and the only published study that infers a value from bicycle helmet use by individuals.

In contrast to the study of bicycle helmet use, Blomquist, Miller, and Levy (1996) and Paul S. Carlin and Robert Sandy (1991) estimate VSL based on statistical analysis of individual micro data that provides evidence of rationality of users of protective equipment. Blomquist, Miller, and Levy incorporate disutility costs associated with use of equipment and estimate VSLs for the typical users rather than upper or lower bounds for users. Elvik notes that these characteristics increase the quality of the studies and estimates.

Motor vehicle models and crashworthiness: An ambitious hedonic study of prices of motor vehicles and associated fatality rates by Timothy Mount, et al. (2001) seeks to 
estimate VSL for household members of different ages. They build upon earlier related analysis by Scott E. Atkinson and Robert Halvorsen (1990) and Mark Dreyfus and W. Kip Viscusi (1995) and devote more attention to household use of the vehicles and distribution within the household. A noteworthy characteristic of the Mount et al. study is the set of detailed estimates of mortality risks that account for differences in vehicle use by various members of households. Another advantage of their study is the inclusion of a wider range of motor vehicles than only passenger cars and a rich set of driver characteristics. Their preliminary estimates of VSL are among the highest of the recent studies. Their point estimate of VSL for adults is $\$ 7.2$ million in 2000 dollars.

Residential location and Superfund sites: Ted Gayer, James T. Hamilton, and W. Kip Viscusi $(2000,2002)$ analyze the housing market surrounding Superfund sites in Grand Rapids, Michigan. They use a specially constructed, expert measure of cancer risk as well as distance measures and other proxies for physical risk. They find that the proxies for risk can explain about half the variation in expert risk and that housing with less (either proxy or expert statistical) risk sells for higher prices. After the release of the EPA Remedial Investigation, premiums for safer locations imply values of statistical cancer of approximately \$4.3-5.0 million in 2000 dollars. Estimates are much higher if prerelease risk perceptions are used. This estimate is especially relevant to BCA of environmental policy because it is inferred from valuing reductions in environmentally-related cancer risks rather than VSL from other averting behavior.

\subsection{Best estimate from recent studies}

As noted at the beginning of this section reviewing recent averting behavior in consumption studies, the range of values for adults is something less than $\$ 1.7$ million to $\$ 7.2$ million in year 2000 dollars as reported in Table 2. The simple average value for adults is approximately $\$ 4.5$ million if $\$ 1.5$ million is used for the speed/fatality study and averages are used for the two studies with a range reported. The range for the best estimates is not much different. Even though Ashenfelter and Greenstone claim that their estimate is an upper bound, some of their own estimates of the average VSL are not much different from their own upper bound. In addition, their estimate is from behavior in traffic and not directly related to behavior related to environmental risks. If their estimate is adjusted for risk misperception, it would be about $\$ 2.8$ million in 2000 dollars. \$2 million could be considered to be at the lower end of the range. The VSL estimate adjusted for risk from Blomquist, Miller, and Levy of \$4.6 million is closer to the average. The VSL estimate adjusted for risk from Mount et al. is $\$ 7.2$ million and could be considered to be at the upper end of the range. The Gayer, Hamilton, and Viscusi estimate of $\$ 4-5$ million for cancer is the estimate most directly related to environmental risks. Presumably the VSL is greater than the value of a statistical case of cancer because not all cancer results in 
death. The best estimate of VSL from averting behavior in consumption is probably close to $\$ 4$ million in year 2000 dollars.

One aspect of the recent estimates worth noting is that the best estimates are greater than values estimated in earlier studies of averting behavior in consumption. One of the reasons for the increase in average values is the greater use of hedonic approaches compared to estimation based on risk related behavior combined with calculations that use other related parameters such as values of time, number of vehicle occupants, and disutility costs. Both types of analysis are valuable. Another reason for the increase is the upward adjustment for underperception of risks.

\section{Risk perception and values implied by averting behavior in household consumption}

A crucial element in estimating VSLs from self-protection and averting behavior is the amount that risk changes when the individual engages in the activity. Atkinson and Halvorsen (1990, fn. 2), for example, explicitly acknowledge that they assume that the automobile purchaser's perception of risk is consistent with actual risk in making their VSL estimates. Their estimates, as do others' estimates shown in Table 2, depend directly on this assumption. It is no secret that individuals can have difficulty understanding risk and making decisions involving risk. However, this imperfection is not fatal for estimating VSL based on observable behavior in product markets and using this information in BCA.

First, an impressive amount of evidence exists that reveals that individuals respond to risk in expected ways. They respond in the expected direction and they respond more, the greater is the risk. Analysis of motorist use of protective equipment such as safety belts and child safety seats, for example, typically shows that motorists protect more when expected benefits are greater such as when traveling at higher speeds and protect less when it costs more such as using child safety seats on older children who should be fitted with larger seats and can protest confinement more effectively, see Glenn C. Blomquist (1991). When individuals have something like their own health and safety at stake, they tend to act as if they perceive risks in ways that indicate their perceptions are positively correlated with expert estimates of the risks.

However well individuals perceive increases and decreases in risk and rank them correctly, their ability to perceive risk in a cardinally correct way is questioned. For example, Sarah Lichtenstein et al. (1978) found that when individuals' perceptions of risks are compared to expert estimates of risks, low risks tend to be overestimated and higher risks tend to be underestimated. Other differences between individual perceptions and expert estimates exist and the relationships have been estimated. Thus, a second reason for thinking that averting behavior is useful despite imperfect perceptions of risk is that, as part of the sensitivity analysis, the estimates of VSL can be adjusted using the relationships between individual perceptions and expert estimates. For example, if individual risk estimates are known to be $20 \%$ lower than the expert risk estimates, then the VSL can be recalculated with the lower risk. The 
rationale is that the lower risk is the level on which the individual is basing behavior and making tradeoffs. Ideally, the individual's perceived risk is the risk appropriate for estimating the VSL. ${ }^{11}$

If the policy maker believes that the adjusted risk is preferred, then the VSL can be estimated based on it. Relying on the Lichtenstein et al. relationship, however, is not wholly satisfactory. Daniel K. Benjamin and William R. Dougan (1997) suggest caution in adjusting risks in this way. They reanalyze the Lichtenstein data and show that differences between individual perceptions and expert estimates disappear if the risks are limited to risks in the person's age group. They find there is no perception "bias." Jahn K. Hakes and W. Kip Viscusi (1997) also reanalyze augmented Lichtenstein et al. data using a Bayesian learning approach. They find that the differences between the individual perceived risks and expert risks are explained by the actual population mean death risk, the discounted lost life expectancy associated with the cause of death, and the age-specific hazard rate. The more specific is the expert, statistical risk estimate is to the individual, the smaller the "bias." If there is no bias, then no adjustment is needed. If something is known about the relationship between individual perceived risk and expert estimates of risk, that relationship can be used in making estimates of the VSL based on averting behavior in consumption. Before the Benjamin and Dougan's reexamination of risk perception bias, Miller (1990) used the Lichtenstein study as the basis for adjusting VSL estimates for perception bias in his critique of wage-risk estimates. Blomquist, Miller and Levy (1996) presented VSL estimates for adults, children, and motorcyclists unadjusted and adjusted for perception bias. After the reexamination of Lichtenstein et al., Miller (2000), in his review and analysis of VSL across countries, uses VSL estimates which are not adjusted for perception bias, but he allows for misperception through various regression specifications. Mount et al. (2001) estimate VSLs for children, adults, and senior adults based on a hedonic analysis of motor vehicle prices and their own extremely detailed estimates of risks of fatal and nonfatal accidents. They report their VSL estimates based on expert statistical risks and on risks corrected for perception bias. They consider their best estimates to be ones based on adjusted risks.

Economists have paid a great deal of attention to perception of environmental risks. V. Kerry Smith and F. Reed Johnson (1988) evaluated how Maine residents form perceptions about radon risks. They found support for a modified form of a Bayesian learning model and further that individuals who took mitigating action reported lower perceived risks. David S. Brookshire et al. (1985) estimated the impact of a risk notification program on perceptions of earthquake risks in the California housing market and found that the implicit values of risk after notification were comparable to the contingent values. Mark Dickie and Shelby Gerking (1996) found that the formation of risk beliefs about skin cancer depends on complexion and sunlight exposure, and link the risk beliefs to estimates of willingness to pay for avoiding skin cancer. W. Kip Viscusi and William N. Evans (1998) studied nonfatal health risks associated with a toilet bowl cleaner and an insecticide. They estimated the relationship between the stated (expert) risk and perceived risk and reported a 
relationship in a way similar to Lichtenstein et al. except that it is for the risks associated with the products being studied. They report the willingness to pay values implied by both the stated risk and stated risk adjusted for perception bias.

Averting behavior through job choice in the labor market provides another example of attention to risk perception. Douglas Gegax, Shelby Gerking, and William Schulze (1991) survey workers to get data on individuals' perceived mortality risks of specific jobs and wages rather than use observed frequencies to estimate occupation or industry average fatality rates. ${ }^{12}$ This study and the other examples illustrate that studies of risk belief about averting behavior and valuation of risks can be combined to obtain better VSL estimates. ${ }^{13}$

The final reason why potential problems with risk misperception are not fatal to estimating VSL based on averting behavior in consumption is that the standard is not one of perfection. Alternative estimates implicit in the labor market and estimates elicited in hypothetical markets can contribute to our understanding of the VSL, but they are not perfect. Another alternative, the democratic process, has much to commend it, but preference revelation through the political process is not perfect either.

Concern about risk perception bias must be thought through carefully. It is straightforward that if perceived risks and expert risks match well for averting behavior studies, then these studies can reveal the values that individuals place on changes in their own mortality risks, and the estimated values can be used in BCA to evaluate environmental programs which reduce similar risks. If risk perceptions are biased and the bias is known, then the values implied by the biased perceptions are the VSL estimates that are appropriate for BCA because they reflect the tradeoff that individuals thought they were making. This adjustment is appropriate if the "correction" can be made in a convincing manner. Agreement with this adjustment probably depends on assessments of how convincing the corrections are. When evidence exists that individuals are willing to pay for perceived risks even though expert estimates are much lower, it poses a policy problem discussed by Gary H. McClelland, William D. Schulze, and Brian Hurd (1990) and Paul R. Portney (1992). The problem is that, from an expert perspective, resources might be wasted. Regardless of this policy problem if the proximate objective is to estimate individual WTP to reduce mortality risk, then VSLs implied by tradeoffs of perceived risk are appropriate.

\section{Values of reductions in mortality risks for children and senior adults}

\subsection{Children}

Children and senior adults are currently of special interest for environmental policy. The review of recent studies shown in Table 2 includes four that estimate VSL for special groups. Carlin and Sandy (1991) analyze mothers' use and nonuse of child safety seats for their children. Based on their analysis they find that their estimates of time and money use costs and external estimates of the reduction in mortality risks 
for the children imply a VSL for children of approximately $\$ 0.8$ million in 2000 dollars. They report that their estimate of mothers' VSL for their children who are under the age of 5 years is approximately $87 \%$ of Glenn C. Blomquist's (1979) estimate of VSL for adult drivers based on use and nonuse of seat belts. While their study is thoughtfully executed, they do not include an estimate for mothers' disutility costs of using child safety seats.

Three studies estimate VSL for both adults and children. Blomquist, Miller, and Levy (1996) analyze motorists' use and nonuse of safety equipment. Their best estimate of VSL for children less than 5 years of age based on use and nonuse of child safety seats and belts stands at $\$ 3.7$ million in 2000 dollars. This value is approximately $32 \%$ greater than the best estimate of VSL for adults of $\$ 2.8$ million based on driver use and nonuse of seat belts. If the imprecisely estimated point estimate for child safety seat use only (not combined with harness use), then the VSL for children is roughly twice the VSL for adults. Jenkins, Owens, and Wiggins (2001) estimate parents' VSL for their bicycling children as approximately $\$ 2.9$ million, a value that is less than the VSL of $\$ 4.3$ million for bicycling adults who buy and use bicycle helmets, but their estimate is based on aggregate data and ignores utility/ disutility of wearing helmets. Mount et al. (2000) estimate VSL based on a hedonic analysis of motor vehicle prices. They use detailed vehicle, driver, and vehicle use data along with an intertemporal adjustment based on Michael J. Moore and W. Kip Viscusi's (1988) article to estimate VSLs for adults and children. Their estimate for children of $\$ 7.3$ million is slightly greater than the estimate for adults of $\$ 7.2$ million. Because the difference for the adults and children is due to the intertemporal adjustment, it is not as convincing as the estimate of that for adults that is based on the detailed vehicle, driver, and use data. After considering the limited number of estimates we have for children, a hunch is that the VSL for children exceeds that for adults by at least one-third.

Given the limited number of estimates of VSL for children, it is worth trying to glean something from the estimates of values of children's health. Mark D. Agee and Thomas D. Crocker (2001) analyze data from the 1991 National Maternal and Infant Health Survey to estimate smokers' substitution rates between own consumption and own health, between own consumption and their children's exposure to tobacco smoke, and between own health and their children's health. They estimate that parents value their children's health twice as much as their own health. The measure of health is parents' rating of child health and not mortality risk, but surely the parents, mostly mothers, perceive that mortality risk increases with poorer health. The risk would be of fatal acute episodes associated with respiratory attacks and of fatal chronic diseases which develop later in children's lives.

Jin-Tan Liu et al. (2000) design and implement a stated preference study in Taiwan to estimate a mother's WTP for medicine that would prevent her from getting another case of the cold she typically gets and her WTP for medicine that would prevent her child from getting another case of the cold the child typically gets. They find that for comparable colds a mother's WTP to prevent her child's cold is approximately twice her WTP to prevent her own cold. A stated preference study of 
acute bronchitis by Mark Dickie and Victoria L. Ulery (2001) also finds parental altruism toward their children and that WTP for avoiding episodes is less for parents than for their children. The value for their children is about twice the value for themselves. These three morbidity studies are consistent with the mortality risk studies of child safety seat/belt use that find that VSLs are greater, or at least not less, for children compared to adults. In light of the decision to have children, accommodate them in labor market choices, and the costly investments in other forms of human capital such as education, perhaps it is not surprising that VSL for children is not less than that for adult parents.

\subsection{Senior adults}

Few estimates of VSL exist for senior adults. The only study that estimates VSL based on self-protection, or averting behavior, in consumption is Mount et al. (2000). Based on a hedonic analysis of motor vehicle prices using detailed vehicle, driver, and vehicle use data and an adjustment using the Moore and Viscusi intertemporal model they estimate that VSL for senior adults is approximately $\$ 5.2$ million. This preliminary estimate is less than the estimate for all adults. However, the difference for seniors is partly due to the intertemporal adjustment.

The only study that estimates a VSL for older adults based on risk compensating wage differentials is by V. Kerry Smith, Mary F. Evans, Hyun Kim, and Donald H. Taylor (forthcoming). Their analysis of data from the Health and Retirement Survey and the Bureau of Labor Statistics yields estimates of VSL for all workers in the sample of approximately \$6 million in year 2000 dollars. This estimate is within the range of estimates reviewed in the Janusz R. Mrozek and Laura R. Taylor (2002) meta-analysis and other labor market studies such as those in Viscusi's (1993) and W. Kip Viscusi and Joseph E. Aldy's (2003) reviews. The Smith et al. VSL estimates for workers who are 51-65 years of age are greater than for all workers and as much as twice the size of VSL for all workers. Their study does not include older seniors such as individuals over 75. More empirical and theoretical research is warranted because these estimates come from one study and are inconsistent with the implications of the life cycle model of VSL as normally interpreted. Implications from the life cycle model are being reconsidered. Recent papers by Johansson $(2001,2002)$, for example, demonstrate that the assertions that there are strong theoretical grounds for the view that VSL falls with age have been overstated. He shows that the implication that VSL declines with age is sensitive to assumptions about consumption over the life cycle. If consumption is not constant, then the VSL can decrease, stay constant, or increase with age.

The stated preference study of Canadian adults by Alan Krupnick et al. (2002) finds lower values for adults than Smith et al. (forthcoming), but a similarity is that they too find that the VSL does not change much with age during the 50s and $60 \mathrm{~s}^{14}$ They find it is about $30 \%$ lower for individuals aged 70 and over compared to younger adults. In another stated preference study, Magnus Johannesson and 
Per-Olov Johansson (1997) elicit a premium Swedish adults are willing to pay for a program that would extend life expectancy by one year conditional upon reaching age 75. They too do not find much change in value with age, but in contrast to Krupnick et al., they find that WTP increases slightly with age.

\subsection{If values differ, should different values be used in policy?}

In addition to future research on VSL for children and senior adults, a formal study of the ethics and practicality of using different VSLs for different groups in BCA would be worthwhile. The theory of using the values of the individuals who receive the benefits and bear the costs of policy is clear when the goal is maximizing efficiency. It is the basis for using individual WTP. However, what is the ethical basis for using population average values in some cases and values of specific subpopulation groups in other cases? If the primary beneficiaries of a policy that improves air quality are smokers and smokers have lower VSL than nonsmokers, is the policy to be evaluated with those lower values? If the primary beneficiaries of remediation of a Superfund site are nonminority poor and the VSL for them is lower than for individuals with higher income, is the policy to be evaluated with those lower values? Liu et al. (2000) find that in Taiwan mothers' WTP for preventing illness is $20 \%$ higher for their sons than for their daughters. If the same relationship is found in the U.S., is EPA going to use higher values for boys? If marital status influences VSL, should different values be used for single, married, and divorced individuals? ${ }^{15}$ Notice how the previous concern for the representativeness of the estimates from a set of individuals is replaced by concern for estimates for individuals with a specified characteristic. It is unclear, however, that policy makers have a well developed conceptual framework for applying the different VSL estimates to policy. A hunch is that a consistent conceptual approach may be one that recognizes that benefit-cost analysis takes place within a particular society and the legal framework of that society, see Richard O. Zerbe (1991). Within such a context different VSL would be used for different types of individuals when evidence shows that the estimates of VSL differ and when the legal and regulatory framework indicates that different values are to be applied.

\section{Comparing estimates from averting behavior in consumption to estimates from the labor market and stated preferences}

The focus of this review is on estimates of VSL based on self-protection or averting behavior in consumption. One aspect of the recent estimates reported in Table 2 that is worth noting is that the simple average of the VSL estimates of $\$ 4.5$ million for adults and what is probably the best estimate of about $\$ 4$ million fall in the range of estimates based on averting behavior in the labor market. \$4 to \$5 million in 2000 dollars is within the range of studies reviewed by Mrozek and Taylor (2002) and Viscusi (1993). It is a bit higher than the estimates in the range of \$1.5-2.5 million 
based on best practice in Mrozek and Taylor, but they place a greater weight on studies that control for more occupation and industry characteristics and those studies tend to yield lower estimates of VSL. The VSL estimate of about \$4 million from averting behavior in consumption is also close to Miller's (2000) average of $\$ 3.9$ million in 2002 dollars based on his review of studies of all three types (consumption, labor, and stated preferences).

Although wage-risk studies have tended to produce estimates of VSL greater than estimates from averting behavior in consumption, there is some reason to believe that the estimates from the labor market are too high. Jason Shogren and Thomas D. Crocker $(1991,1999)$ emphasize the importance of endogenous environmental risk and its implications for self-protection as a lower bound on the value of risk reductions. Jason Shogren and Tommy Stamland (2002) offer a reason for upward bias in risk compensating wage studies. They demonstrate that if workers differ in their individual, private ability to reduce risk and the ability is unobservable by employers, then a market wage must be offered to attract the marginal worker who faces the most risk of those employed. If the average risk of all workers is used to estimate a VSL, then risk is lower than that faced by the marginal worker and the VSL estimate is biased upward. If unbiased estimates from the labor market are even lower than the meta-analysis of Mrozek and Taylor indicates, then more thought about the difference between them and the higher estimates from the recent averting behavior studies is warranted.

The de Blaeij et al. (2000) meta-analysis of estimates of VSL finds that stated preference, or contingent valuation, studies yield higher estimates of VSL than estimates of VSL implied in studies of self-protection or averting behavior. Miller (2000) reports coefficients from his regression meta-analysis that imply that VSL estimates based on wage-risk tradeoffs are significantly and substantially higher than the VSL estimates based on averting behavior in consumption. He finds that the VSL estimates based on stated preferences are higher yet. Stated preference studies in their rawest form are subject to "yea saying" hypothetical bias. For example, for the simple, hypothetical purchase of the private good, sunglasses, Karen Blumenschein et al. (1998) find strong evidence of hypothetical bias relative to actual purchases. Significant numbers of individuals say they will purchase at the stated price, and then, in fact, do not purchase when given the opportunity. One explanation for the stated preference VSLs being greater than the implied VSLs is that early stated preference studies did not include specific countermeasures to "yea saying" that have been developed recently. If recent research including such countermeasures is indicative, then future stated preference studies need not yield estimates of the VSL which are greater than values implied by averting behavior due to hypothetical bias. Presumably if a countermeasure to hypothetical bias such as cheap talk and calibration by stated certainty continue to be effective and others are developed, then a future meta-analysis of VSL would show less difference between stated preference and averting behavior estimates. Other factors may cause estimates from the approaches to differ, but the contribution of hypothetical bias will shrink if countermeasures are effective. ${ }^{16}$ 


\section{The research portfolio and behavior in the household}

Valuing life may appear to be impossible, but for practical purposes it is straightforward. People, as individuals and as societies, make choices all the time in which they implicitly make tradeoffs between changes in their mortality risks and valuable time and money. Estimates of these values of changes in mortality risks, or alternatively, values of statistical lives, come from analyses of jobs with different wages and risks, household consumption decisions involving changes in risk and time and money, and from direct questioning involving risk-money tradeoffs in constructed or experimental markets. The estimates come from a large number and a wide variety of studies. This broad nature of the evidence is a strength.

To ignore the prospect of new information from observable consumption behavior and to rely on only one approach would indicate a lack of appreciation for how current understanding was achieved. To invest in research on only one type, say stated preference, would make the research investment portfolio a risky one. Estimates of the VSL based on willingness to pay are considerably more reliable than, say, 20 years ago. When the whole of the literature on VSL is viewed, its strength lies in the quantity and variety of estimates (see Glenn C. Blomquist, 2001). Future research should include a variety of approaches including averting behavior in consumption. Despite the considerable effort that has gone into estimating some components in many studies, more research should be done on some of the components such as disutility costs and risk perception for the household activity from which VSLs will be inferred. Tension exists between scholars probing the edges of our understanding and practitioners who must make decisions and defend them in the face of demand for perfect estimates. A tendency is to favor one method as the best and defend it. Because we do not know exactly what future research will bring, the temptation to pursue a strategy of investing in only the "best" method is risky. Prudent investors who are at all risk averse diversify. Research on self-protection and averting behavior in household consumption decisions should be a vital part of current and future research on valuing mortality risks.

\section{Notes}

1. The ethical foundation for benefit cost analysis can be found in teleology. One form of teleology is utilitarianism in which goodness can be judged on the basis of choosing alternatives that maximize the good for all. A deontologist, in contrast, might object that any tradeoff of risk for money or time is morally objectionable and the concept of VSL for use in BCA is wrong; see Sherry I. Brandt-Rauf and Paul W. Brandt-Rauf (1980).

2. If we fail to emphasize what we know and what we agree on while striving to improve the practice of economics, we risk having the whole approach dismissed as we are viewed as just squabbling, see The Economist (1997).

3. V. Kerry Smith's (1991) "Household Production Functions and Environmental Benefit Estimation" and A. Myrick Freeman's (2003, Chapter 4) "Revealed Preference Models of Valuation: Basic Theory" provide broad reviews of the theory and use of household production approaches to valuing 
environmental changes. These chapters reflect, in part, the fundamental influence of the individual, household approach in benefit estimation in environmental economics. Freeman's (2003, Chapter 10) "Valuing Longevity and Health" provides a careful review of approaches to valuing changes in health risks, and in particular, to estimating values of changes in mortality risks, VSLs. The literature is well developed and will not be reviewed again in this paper.

4. The model is only sketched here. For a more complete presentation see Blomquist (1979). For a more complete discussion of this approach including refinements, see Freeman (2003, Chapter 10).

5. See Freeman (2003, Chapter 10) for a more complete presentation of life cycle models. The list of implications given above is based on his summary on page 311. See Rosen (1988) also.

6. For early reviews see Glenn C. Blomquist (1981, 1982), Michael W. Jones-Lee (1985) and Ann Fisher, Dan Violette, and Lauraine Chestnut (1989).

7. Throughout this paper estimates are reported in 2000 U.S. dollars. The annual average Consumer Price Index for all urban consumers for all items is used to convert values from studies with VSL reported in dollars for another year.

8. The countries are Australia, Austria, Canada, Denmark, France, Japan, New Zealand, South Korea, Sweden, Switzerland, Taiwan, and the United Kingdom.

9. While one can question the assumption and attempt to obtain the subjective estimates of risk or adjust for perception bias, the tradeoff is no more ex post than the typical estimate from self protection and averting behavior in the labor market.

10. Ghosh, Lees, and Seal (1975) used observed speeds on British motorways to estimate VSL 26 years ago and their estimate is $\$ 1.1$ million in 2002 dollars. Although it is not as sophisticated as Ashenfelter and Greenstone's, both averting behavior studies contribute to what is now considered known, that VSL is greater than discounted foregone earnings.

11. In Blomquist (1982) the Lichtenstein et al. (1978) estimated relationship is used to adjust estimates of the VSL and offer policy makers an alternative to VSL estimates based on expert risk estimates.

12. Mrozek and Taylor (2002) find in their meta-analysis that the estimated effect of using worker's selfassessed risk on the VSL estimates is not robust across specifications. However, in their sample only the Gegax, Gerking, and Schulze (1991) and Moore and Viscusi (1988) studies used perceived risk. They define their best estimates based on studies using expert risk because of their concern that too few wage-risk studies use perceived risk.

13. Misperception of the risk level need not be equal to misperception of the change in risk. However, correct perception of the level of risk is more important in that mortality risks vary by orders of magnitude and gross misperception of the level will dominate misperception of the change even if it is by as much as a half. Another reason for interest in perception of risk levels is that correct perceptions of the levels of risk before and after a change will lead to correct perception of the change in risk.

14. If the emphasis is on quality of life, an alternative to using different VSL for individuals who differ in age would be estimate QALYs directly, see Magnus Johannesson (1996).

15. Shoshana Grossbard-Shecthman (1993) addresses the influence of marital status and the value of homemaker's time.

16. A "cheap talk" script about how individuals tend to say yes appears to have mitigated the tendency to say yes in experiments about contributions for environmental goods, see Ronald G. Cummings and Laura O. Taylor (1999). For calibration of responses by self ratings of certainty of purchase, see Patricia A. Champ et al. (1997) and Blumenschein et al. (1998, 2001).

\section{References}

Agee, Mark D. and Thomas D. Crocker. (2001). "Smoking Parents' Valuations of Own and Children's Health." Presented at the Association of Environmental and Resource Economists Workshop "Assessing and Managing Environmental and Public Health Risks. Bar Harbor, ME, June 13-15.

Ashenfelter, Orley and Michael Greenstone. (2002). "Using Mandated Speed Limits to Measure the Value of a Statistical Life." Presented at the session in honor of the memory of Sherwin Rosen at the AERE/ 
ASSA meetings held January 3-5, 2003 Washington, DC. Available as NBER Working Paper 9094, August 2002.

Atkinson, Scott E. and Robert Halvorsen. (1990). "The Valuation of Risks to Life: Evidence from the Market for Automobiles." Review of Economics and Statistics 72, 133-136.

Becker, Gary S. (1965). "A Theory of the Allocation of Time." Economic Journal 75, 493-517.

Benjamin, Daniel K. and William R. Dougan. (1997). "Individuals' Estimates of Risks of Death: Part I: A Reassessment of the Previous Evidence." Journal of Risk and Uncertainty 15, 115-133.

Blomquist, Glenn C. (2001). "Economics of Value of Life." In the Economics Section edited by Orley Ashenfelter of Neil J. Smelser and Paul B. Baltes (eds.), International Encyclopedia of the Social and Behavioral Sciences. New York: Pergamon of Elsevier Science.

Blomquist, Glenn C. (1979). "Value of Life Saving: Implications of Consumption Activity." Journal of Political Economy 87, 540-558.

Blomquist, Glenn C. (1981). "The Value of Human Life: An Empirical Perspective,” Economic Inquiry 19, 157-164.

Blomquist, Glenn C. (1982). "Estimating the Value of Life and Safety: Recent Developments," In Michael Jones-Lee (ed.), The Value of Life and Safety. Amsterdam: North-Holland Publishing Co.

Blomquist, Glenn C. (1991). "Motorist Use of Safety Equipment: Expected Benefits or Risk Incompetence?" Journal of Risk and Uncertainty 4, 135-152.

Blomquist, Glenn C., Ted R. Miller, and David T. Levy. (1996). "Values of Risk Reduction Implied by Motorist Use of Protection Equipment: New Evidence from Different Populations." Journal of Transport Economics and Policy 30, 55-66.

Blumenschein, Karen, Magnus Johannesson, Glenn Blomquist, Bengt Liljas, and Richard M. O'Conor. (1998). "Experimental Results on Expressed Certainty and Hypothetical Bias in Contingent Valuation." Southern Economic Journal 65, 169-177.

Blumenschein, Karen, Magnus Johannesson, Krista K. Yokoyama, and Patricia R. Freeman. (2001). "Hypothetical versus Real Willingness to Pay in the Health Care Sector: Results from a Field Experiment" Journal of Health Economics 20, 441-457.

Brandt-Rauf, Sherry I. and Paul W. Brandt-Rauf. (1980). "Occupational Health Ethics: OSHA and the Courts." Journal of Health Politics, Policy, and Law 5, 523-534.

Bresnahan, Brian W. and Mark Dickie. (1995). "Averting Behavior and Policy Evaluation." Journal of Environmental Economics and Management 29, 378-92.

Brookshire, David S., Mark Thayer, John Tschirhart, and William Schulze. (1985). "A Test of the Expected Utility Model: Evidence from Earthquake Risks." Journal of Political Economy 93(2), 369389.

Carlin, Paul S. and Robert Sandy. (1991). "Estimating the Value of a Young Child's Life." Southern Economic Journal 58, 186-202.

Champ, P.A., R.C. Bishop, T.C. Brown, and D.W. McCollum. (1992). "Using Donation Mechanism to Value Nonuse Benefits from Public Goods." Journal of Environmental Economics and Management 33, $151-162$.

Cummings, Ronald G. and Laura O. Taylor. (1999) "Unbiased Value Estimates for Environmental Goods: A Cheap Talk Design for the Contingent Valuation Method." American Economic Review 89, $649-665$.

de Blaeij, Arianne, Raymond J.G.M. Florax, Piet Rietveld, and Erik Verhoef. (2002). "The Value of Statistical Life in Road Safety: A Meta-Analysis.” Tinbergen Institute Discussion Paper, TI 2000-089/3, 2000 and revised (2002).

Dickie, Mark and Shelby Gerking. (1996). "Formation of Risk Beliefs, Joint Production and Willingness to Pay to Avoid Skin Cancer." Review of Economics and Statistics 78(3), 451-464.

Dickie, Mark and Victoria L. Ulery. (2001). "Valuing Health in the Household: Are Kids Worth More than Adults?" Presented at the Association of Environmental and Resource Economists Workshop "Assessing and Managing Environmental and Public Health Risks." Bar Harbor, ME, June 1315. 
Dreyfus, Mark Kallison and W. Kip Viscusi. (1995). "Rates of Time Preference and Consumer Valuation of Automobile Safety and Fuel Efficiency." Journal of Law and Economics 38, 79-105.

Elvik, Rune. (1995). "A Meta-Analysis of Value of Life Estimates for Occupational and Transport Safety." Oslo, Norway: Institute of Transport Economics.

Ehrlich, Isaac and Gary S. Becker. (1972). "Market Insurance, Self-Insurance, and Self-Protection." Journal of Political Economy 80, 623-648.

Freeman, A. Myrick III. (2003). The Measurement of Environmental and Resource Values: Theory and Methods, 2nd edn. Washington, DC: Resources for the Future.

Fisher, Ann, Dan Violette, and Lauraine Chestnut. (1989). "The Value of Reducing Risks to Death: A Note on New Evidence." Journal of Policy Analysis and Management 8, 88-100.

Gayer, Ted, James T. Hamilton, and W. Kip Viscusi. (2000). "Private Values of Risk Tradeoffs at Superfund Sites: Housing Market Evidence on Learning about Risk." Review of Economics and Statistics 82, 439-451.

Gayer, Ted, James T. Hamilton, and W. Kip Viscusi. (2002). "The Market Value of Reducing Cancer Risk: Hedonic Housing Prices with Changing Information." Southern Economic Journal 69, 266-289.

Gegax, Douglas, Shelby Gerking, and William Schulze. (1991). "Perceived Risk and the Marginal Value of Safety." Review of Economics and Statistics 73, 589-596.

Ghosh, Debapriya, Dennis Lees, and William Seal. (1975). "Optimal Motorway Speed and Some Valuations of Time and Life." Manchester School of Economic and Social Studies 43(2), 134-143.

Grossbard-Shechtman, Shoshana. (1993). On the Economics of Marriage - A Theory of Marriage, Labor and Divorce. Boulder, CO: Westview Press.

Hakes, Jahn K. and W. Kip Viscusi. (1997). "Mortality Risk Perceptions: A Bayesian Reassessment." Journal of Risk and Uncertainty 15, 135-150.

Jenkins, Robin R, Nicole Owens, and Lanelle Bembenek Wiggins. (2001). "Valuing Reduced Risks to Children: The Case of Bicycle Safety Helmets." Contemporary Economic Policy 19(4), 397-408.

Johannesson, Magnus. (1996). Theory and Methods of Economic Evaluation of Health Care. Boston, MA: Kluwer Academic Publishers.

Johansson, Per-Olov. (2001). "Is There a Meaningful Definition of the Value of a Statistical Life?" Journal of Health Economics 20, 131-139.

Johansson, Per-Olov. (2002). "On the Definition and Age-Dependency of the Value of a Statistical Life." Journal of Risk and Uncertainty 25, 251-263.

Johannesson, Magnus and Per-Olov Johansson. (1997). "Quality of Life and the WTP for an Increased Life Expectancy at an Advanced Age." Journal of Public Economics 65, 219-228.

Jones-Lee, Michael W. (1977). "Some Empirical Rigor Mortis: An Empirical Procedure for Estimating the Value of Life from Tyre Replacement Data." Presented at the SSRC Health Economists' Study Group at University of Newcastle-Upon-Tyne in July.

Jones-Lee, Michael W. (1985). "The Value of Life and Safety: A Survey of Recent Developments." The Geneva Papers on Risk and Insurance 10, 141-173.

Jondrow, James, Marianne Bowes, and Robert Levy. (1983). "The Optimal Speed Limit." Economic Inquiry 21, 325-336.

Krupnick, Alan, Anna Alberini, Maureen Cropper, Nathalie Simon, Bernie O'Brien, Ron Goeree, and Martin Heintzerman. (2002). "Age, Health and the Willingness to Pay for Mortality Risk Reductions: A Contingent Valuation Survey of Ontario Residents." Journal of Risk and Uncertainty 24, 161186.

Lichtenstein, Sarah, et al. (1978). "Judged Frequency of Lethal Events." Journal of Experimental Psychology: Human Learning and Memory 4, 551-578.

Liu, Jin-Tan, James K. Hammitt, Jung_Der Wang, and Jin_Long Liu. (2000). "Mother's Willingness to Pay for Her Own and Her Child's Health: A Contingent Valuation Study in Taiwan." Health Economics 9, 319-326.

McClelland, Gary H., William D. Schulze, and Brian Hurd. (1990). "The Effect of Risk Beliefs on Property Values: A Case Study of a Hazardous Waste Site.” Risk Analysis 10, 485-497. 
Miller, Ted R. (1990). "The Plausible Range for the Value of Life - Red Herrings among the Mackerel." Journal of Forensic Economics 3, 17-40.

Miller, Ted R. (2000). "Variations between Countries in Values of Statistical Life." Journal of Transport Economics and Policy 34(2), 169-188.

Mincer, Jacob. (1962). "Labor Force Participation of Married Women: A Study of Labor Supply." In H. Gregg Lewis (ed.), Aspects of Labor Economics. Princeton, NJ: Princeton University Press. Reprinted in Studies in Labor Supply, Collected Essays of Jacob Mincer, Vol. 2. Aldershot U.K.: Edward Elgar (1993).

Mincer, Jacob. (1963). "Market Prices, Opportunity Costs, and Income Effects." In C. Christ (ed.), Measurement in Economics. Stanford, CA: Stanford University Press. Reprinted in Studies in Labor Supply, Collected Essays of Jacob Mincer, Vol. 2. Aldershot U.K.: Edward Elgar (1993).

Moore, M.J. and W.K. Viscusi. (1988). "The Quantity-Adjusted Value of Life.” Economic Inquiry 26, 369388.

Mount, Timothy, Weifeng Weng, William Schulze, and Laurie Chestnut. (2001). "Automobile Safety and the Value of Statistical Life in the Family: Valuing Reduced Risk for Children, Adults, and the Elderly." Presented at the Association of Environmental and Resource Economists Workshop "Assessing and Managing Environmental and Public Health Risks," Bar Harbor, ME, June 13-15.

Mrozek, Janusz R. and Laura O. Taylor. (2002). "What Determines the Value of Life? A Meta-Analysis." Journal of Policy Analysis and Management 21, 253-270.

Portney, Paul R. (1992). "Trouble in Happyville.” Journal of Policy Analysis and Management 11, 131132.

Rosen, Sherwin. (1988). "The Value of Changes in Life Expectancy." Journal of Risk and Uncertainty 1, 285-304.

Shogren, Jason and Thomas D. Crocker. (1991) "Risk, Self-Protection, and Ex Ante Economic Value." Journal of Environmental Economics and Management 20, 1-15.

Shogren, Jason and Thomas D. Crocker. (1999). "Risk and Its Consequences." Journal of Environmental Economics and Management 37, 44-51.

Shogren, Jason and Tommy Stamland. (2002). "Skill and the Value of Life" Presented at the Association of Environmental and Resource Economists Workshop "Assessing and Managing Environmental and Public Health Risks,” Bar Harbor, ME, June 13-15, 2001. Journal of Political Economy 110, 1168-1173.

Smith, V. Kerry. (1991). "Household Production Functions and Environmental Benefit Estimation." In J.B. Braden and C.D. Kolstad (eds.), Measuring the Demand for Environmental Quality. New York, NY: North Holland.

Smith, V. Kerry and F. Reed Johnson. (1988). "How Do Risk Perceptions Respond to Information? The Case of Radon." Review of Economics and Statistics 70, 1-8.

Smith, V. Kerry, Mary F. Evans, Hyun Kim, et al. (Forthcoming). "Do the 'Near' Elderly Value Mortality Risks Differently?" Review of Economics and Statistics.

The Economist. (1997). "The Puzzling Failure of Economics." August 23, 11.

Viscusi, W. Kip. (1993). "The Value of Risks to Life and Health." Journal of Economic Literature 31, $1912-1946$

Viscusi, W. Kip and Joseph E. Aldy. (2003). "The Value of a Statistical Life: A Critical Review of Market Estimates throughout the World" Presented at the session in honor of the memory of Sherwin Rosen at the AERE/ASSA meetings held January 3-5 in Washington, DC. Journal of Risk and Uncertainty 27, 576.

Viscusi, W. Kip and William N. Evans. (1998). "Estimation of Revealed Probabilities and Utility Functions for Product Safety Decisions." Review of Economics and Statistics 80, 28-33.

Winston, Clifford and Fred Mannering. (1984). "Consumer Demand for Automobile Safety." American Economic Review 74, 316-319.

Zerbe Jr., Richard O. (1991). "Comment: Does Benefit Cost Analysis Stand Alone? Rights and Standing." Journal of Policy Analysis and Management 10, 96-105. 